\title{
Molecular Docking Analysis of $\alpha$-Tomatine and Tomatidine to Inhibit Epidermal Growth Factor Receptor (EGFR) Activation in Non-Small-Cell Lung Cancer (NSCLC)
}

\author{
Intan Fitri Amalia ${ }^{1 *}$, Assyifa Sayyidah ${ }^{1}$, Kirana Aisyah Larasati $^{1}$, Sarah Fadilah Budiarti ${ }^{1}$ \\ ${ }^{1}$ Department of Biology, Faculty of Mathematics and Natural Science, Brawijaya University, Veteran Street, Malang, East Java, \\ Indonesia, 65145
}

Submission: June 2020; Revised: July 2020; Accepted: October 2020

*Corresponding author: Intan Fitri Amalia; e-mail: intanfitriamalia810@gmail.com; tel.: 081234492181

\begin{abstract}
The use of chemical drugs is the most frequent option for NSCLC therapy but most of it has side effects, such as diarrhea, skin problems, excessive body feeling, and soreness of the mouth. Therefore, NSCLC therapy using herbal medicine from plant bioactive compounds began to be developed to minimize the side effect of chemical drug consumption. Tomato (Lycopersicon esculentum Mill.) is one of the herbal sources which contains bioactive compounds such as $\alpha$-tomatine and tomatidine. This study aimed to analyze the effectiveness of $\alpha$-tomatine, tomatidine, and a combination of both to inhibit EGFR activity by molecular docking. The ligand and protein preparations were done using Discovery Studio 2016 and Hex 8.0.0 for docking. Visualization was done using Discovery Studio 2016 as well. Alpha tomatine, tomatidine, and combination of both have the potential to inhibit the interaction between EGFR and EGF as native ligands. Combination of $\alpha$-tomatine and tomatidine had the best results among other complexes that have been tested with a thread of a-tomatine applied before tomatidine. Alpha tomatine and tomatidine can be considered as drugs that can control the overexpression of EGFR and decrease the activation of one of the lung cancers signaling pathways.
\end{abstract}

Keywords: alpha-tomatine, EGF, EGFR, NSCLC, tomatidine.

\section{INTRODUCTION}

Cancer is the second leading disease that causes death in the world. About 1 in 6 deaths is due to cancer [1]. Lung cancer is one type of cancer that has a high occurrence of death. Lung cancer also ranks second in the category of new cancer cases that affect both men and women [2]. One common subtype of lung cancer include nonsmall cell lung cancer (NSCLC) which is responsible for approximately $85-90 \%$ new cases of lung cancer [3].

Molecular markers of NSCLC are found to be overexpressed. One of which is the epidermal growth factor (EGFR). Increasing number of EGFRs on the cell surface in NSCLC patients can occur $19 \%$ to $89 \%$ from normal condition [4]. Occurrence of EGFRs overexpression is fairly high. Approximately, 62\% NSCLCs is due to EGFRs overexpression [5]. Hence, choosing EGFR as a target protein will give a chance to reduce the mortality rate due to NSCLC.

Nowadays, the use of chemical medicine is a common option to undertake NSCLC therapy. Gefitinib is of that drug that specifically and efficiently targets the mutated EGFRs. However, gefitinib has side effects, such as causing diarrhea, skin problems, excessive body feeling, and soreness of the mouth [6]. Therefore, NSCLC therapy using herbal medicine from plant bioactive compounds began to be developed to minimize the side effect of chemical medicine consumption. Tomato (Lycopersicon esculentum Mill.) is one of the herbal sources. Tomatoes contain bioactive compounds such as $\alpha$-tomatine that has therapeutic value for lung cancer treatment and induce apoptosis [7], inhibit tumor development [8]; and tomatidine that can inhibit migration and invasion of A548 adenocarcinoma cells in human lung cancer [9]. Even if tomatidine gives effect in migration and invasion of human adenocarcinoma cells lung cancer, in this miniproject we tried to find out the effect of tomatidine before the cancer becomes malignant.

This study aimed to analyze the effectiveness of $\alpha$-tomatine, tomatidine, and combination of both to inhibit EGFR activity. This project was expected to reveal the potential of tomato as herbal medicine for cancer therapy. The results can be used as additional information for NSCLC therapy using plant bioactive compounds.

\section{METHODS}

\section{Receptor and Ligand Preparations}

EGFR (ID: 1IVO) and EGF (ID: 2kv4) were downloaded from PDB database (www.rcsb.org). EGFR was prepared by Discovery Studio 2016 [10] to remove ligand contaminants and water molecules. Tomatidine (CID: 65576) ligand were 
obtained from PubChem database tomatine (CID: 28523) ligand was modeled by 3D modeler [11] based on $\alpha$-tomatine (ID: 28523) canonical SMILE. Ligand's energy was minimized and converted to PDB format by PyRx 0.8 [12].

\section{Receptor-Ligand Docking and Visualization}

The docking of protein-ligand was done using Hex 8.0 [13]. In this project, we established several interactions such as EGFR +EGF, EGFR $+\alpha$-tomatine, EGFR +tomatidine, EGFR $+\alpha-$ tomatine+ EGF, EGFR +tomatidine+ EGF, EGFR + tomatidine $+\alpha$-tomatine + EGF, and EGFR $+\alpha-$ tomatine+tomatidin+ EGF. The correlation type used in this docking was Shape+ DARS. The outputs of docking were visualized by Discovery Studio 2016 [10] to analyze the interactions.

\section{RESULTS AND DISCUSSIONS}

EGF as the native ligand of EGFR interacted on several EGFR amino acid residues includes His409, Gly410, Met30, Leu38, Gly39, Gly9, Cys7, Asn40, and Val37 with total binding energy $-629,3 \mathrm{kcal} / \mathrm{mol}$ (Figure 1). Nearly all of these interactions bind the EGFR Domain I in amino acids 1-133 which shows that EGF binds to the EGFR Domain participating in ligand binding [14]. Interaction between EGFR and $\alpha$-tomatine established 4 hydrogen bonds and 2 hydrophobic bonds with total binding energy $-507,4 \mathrm{kcal} / \mathrm{mol}$ (Table 1). Those interactions were bound with 5 amino acid residues such as Lys69, Lys270, Cys267, Lys407, and Tyr251 outside of EGFR binding site (Figure 2). Although $\alpha$-tomatine was not bound in the active site of EGFR, this compound proved to inhibit the migration and invasion of lung cancer cells by inactivating FAK/PI3K/Akt and Erk signaling pathways which shown a decrease in the binding activity of NF- $\mathrm{KB}$ [15]. In conclucion, $\alpha$-tomatine had not the effect of inhibiting NSCLC through EGFR pathway. However, it suspected to be inhibited NSCLC through FAK/PI3K/Akt and Erk signaling pathways.

Tomatidine interacted with 6 amino acid residues with total binding energy $-307.7 \mathrm{kcal} / \mathrm{mol}$ (Table 1). Tomatidine form hydrogen bonds with Arg405 and Leu38 which indicate that there is a strong bond established between the ligand and active site of EGFR located in Domains I and III (Figure 2). These results indicate tomatidine had the potential to block EGFR binding site. The EGFR-tomatidine complex interacted with EGF had total binding energy of $-657.2 \mathrm{kcal} / \mathrm{mol}$ (Table 1). This complex may reduce EGFR activity by forming 2 hydrophobic bonds in Leu38 and Met87 which are the active site of EGFR (Figure (pubchem.ncbi.nlm.nih.gov/) as 3D-SDF. The $\alpha$ 2). EGF which interacted with EGFR- $\alpha$ tomatine complex had $-678.5 \mathrm{kcal} / \mathrm{mol}$ of total binding energy. A hydrophobic bond was formed at the active site of EGFR (Figure 2). Just like the EGFR-tomatidine-EGF complex, this complex may reduce EGFR activity. EGF in the compound combination complex EGFR-tomatidine- $\alpha$ tomatine-EGF had a total binding energy of $664.7 \mathrm{kcal} / \mathrm{mol}$ (Table 1). In this complex, EGF formed 2 amino acid bonds, conventional hydrogen bond and alkyl bond in Domains III involved $\mathrm{Arg} 405$ and Lys407 respectively (Figure 2). This combination also established 5 amino acid bonds in Domains II or non-binding sites. On the other hand, the complex of EGFR- $\alpha$ tomatinetomatidine-EGF had a total binding energy of $669.1 \mathrm{kcal} / \mathrm{mol}$. This interaction involved an amino acid residue Lys407 bond in binding site (Domains III) (Table 1). The thread of $\alpha$-tomatine before tomatidine treatment showed the best result for compound combination to inhibit EGF binding. a

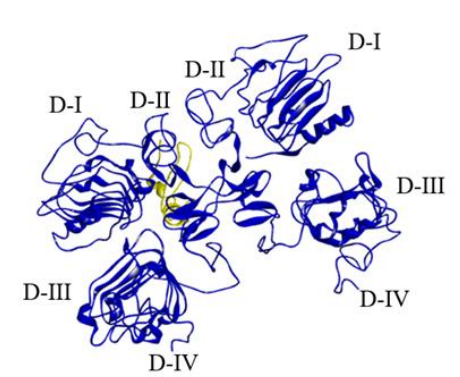



Figure 1. Interaction Between EGFR with 4 domains (D-I: domain I; D-II: domain II; D-III: domain III; and D-IV: domain IV) and EGF as Native Ligand, its binding location (a) and ligand interaction (b)

The epidermal growth factor receptor (EGFR) is a tyrosine kinase receptor which belongs to ErbB receptor family. EGFR also known as ErbB1 or HER1. EGFR is involved in a variety of cellular processes including cell proliferation, motility, survival, and differentiation. The aberrant activation due to upregulation of EGFR is implicated in a variety of human cancers such as non-small-cell lung cancer, metastatic colorectal cancer, glioblastoma, head and neck cancer, pancreatic cancer, and breast cancer. The receptor is activated by the binding of various ligands including epidermal growth factor (EGF). EGFR is a single-pass transmembrane protein consist of an extracellular domains, a transmembrane domains, a juxta membrane segment, a kinase domains, and a C-terminal regulatory tail. The extracellular ligand-binding domains of EGFR contains 4 distinct Domains IIV. Both Domains I (also known as L1) and III (or L2) have a helix solenoid structure, which is 
related to the leucine-rich repeat superfamily and are responsible for ligand binding through simultaneous contact to the same bound ligand $[14,16]$.

Table 1. Molecular interaction of EGFR amino acid residues among ligands

\begin{tabular}{|c|c|c|c|c|c|}
\hline Interaction & Point Interaction & $\begin{array}{l}\text { Distance } \\
\quad(\AA)\end{array}$ & Type & $\begin{array}{l}\text { Chemistry } \\
\text { Bond }\end{array}$ & $\begin{array}{c}\text { Energy } \\
\text { Binding } \\
(\mathrm{kcal} / \mathrm{mol})\end{array}$ \\
\hline \multirow{6}{*}{$\begin{array}{l}\text { EGFR }+\alpha- \\
\text { tomatine }\end{array}$} & A:LYS269:HN - :UNK0:O14 & 2.93 & $\begin{array}{l}\text { Conventional } \\
\text { Hydrogen Bond }\end{array}$ & $\begin{array}{l}\text { Hydrogen } \\
\text { Bond }\end{array}$ & \multirow{6}{*}{-507.4} \\
\hline & A:LYS270:HZ1 - :UNK0:O16 & 2.89 & $\begin{array}{l}\text { Conventional } \\
\text { Hydrogen Bond }\end{array}$ & $\begin{array}{l}\text { Hydrogen } \\
\text { Bond }\end{array}$ & \\
\hline & :UNK0:H154 - A:CYS267:O & 2.52 & $\begin{array}{l}\text { Conventional } \\
\text { Hydrogen Bond }\end{array}$ & $\begin{array}{l}\text { Hydrogen } \\
\text { Bond }\end{array}$ & \\
\hline & : UNK0:H147 - A:CYS267:O & 2.98 & $\begin{array}{l}\text { Carbon Hydrogen } \\
\text { Bond }\end{array}$ & $\begin{array}{l}\text { Hydrogen } \\
\text { Bond }\end{array}$ & \\
\hline & A:LYS407 - :UNK0 & 4.67 & Alkyl & Hydrophobic & \\
\hline & B:TYR251 - :UNK0:C41 & 5.26 & Pi-Alkyl & Hydrophobic & \\
\hline \multirow{6}{*}{$\begin{array}{l}\text { EGFR + } \\
\text { tomatidine }\end{array}$} & :LIG1:H - A:ARG405:O & 2.57 & $\begin{array}{l}\text { Conventional } \\
\text { Hydrogen Bond }\end{array}$ & $\begin{array}{l}\text { Hydrogen } \\
\text { Bond }\end{array}$ & \multirow{6}{*}{--307.7} \\
\hline & :LIG1:H - A:LEU38:O & 2.42 & $\begin{array}{l}\text { Carbon Hydrogen } \\
\text { Bond }\end{array}$ & $\begin{array}{l}\text { Hydrogen } \\
\text { Bond }\end{array}$ & \\
\hline & :LIG1:C - A:LYS407 & 3.68 & Alkyl & Hydrophobic & \\
\hline & :LIG1:C - A:PRO272 & 3.98 & Alkyl & Hydrophobic & \\
\hline & A:PHE263 - :LIG1:C & 5.30 & Pi-Alkyl & Hydrophobic & \\
\hline & B:TYR251 - :LIG1 & 5.422 & Pi-Alkyl & Hydrophobic & \\
\hline \multirow{6}{*}{$\begin{array}{l}\text { EGFR }+\alpha- \\
\text { tomatine + } \\
\text { EGF }\end{array}$} & A:LYS269:HN - B:UNK0:O14 & 2.93 & $\begin{array}{l}\text { Conventional } \\
\text { Hydrogen Bond }\end{array}$ & $\begin{array}{l}\text { Hydrogen } \\
\text { Bond }\end{array}$ & \multirow{6}{*}{-678.5} \\
\hline & $\begin{array}{l}\text { A:LYS270:HZ1 - } \\
\text { B:UNK0:O16 }\end{array}$ & 2.89 & $\begin{array}{l}\text { Conventional } \\
\text { Hydrogen Bond }\end{array}$ & $\begin{array}{l}\text { Hydrogen } \\
\text { Bond }\end{array}$ & \\
\hline & B:UNK0:H154 - A:CYS267:O & 2.52 & $\begin{array}{l}\text { Conventional } \\
\text { Hydrogen Bond }\end{array}$ & $\begin{array}{l}\text { Hydrogen } \\
\text { Bond }\end{array}$ & \\
\hline & B:UNK0:H147 - A:CYS267:O & 2.98 & $\begin{array}{l}\text { Carbon Hydrogen } \\
\text { Bond }\end{array}$ & $\begin{array}{l}\text { Hydrogen } \\
\text { Bond }\end{array}$ & \\
\hline & A:LYS407 - B:UNK0 & 4.66 & Alkyl & Hydrophobic & \\
\hline & B:TYR251 - B:UNK0:C41 & 5.26 & Pi-Alkyl & Hydrophobic & \\
\hline \multirow{9}{*}{$\begin{array}{l}\text { EGFR + } \\
\text { tomatidine } \\
+ \text { EGF }\end{array}$} & B:LIG1:H - A:THR249:O & 1.67 & $\begin{array}{l}\text { Carbon Hydrogen } \\
\text { Bond }\end{array}$ & $\begin{array}{l}\text { Hydrogen } \\
\text { Bond }\end{array}$ & \multirow{9}{*}{-657.2} \\
\hline & B:LEU38 - B:LIG1 & 4.09 & Alkyl & Hydrophobic & \\
\hline & B:LIG1:C - B:LEU38 & 4.58 & Alkyl & Hydrophobic & \\
\hline & B:LIG1:C - B:LEU38 & 4.28 & Alkyl & Hydrophobic & \\
\hline & B:LIG1:C - B:MET87 & 4.52 & Alkyl & Hydrophobic & \\
\hline & B:LIG1:C - B:MET87 & 3.27 & Alkyl & Hydrophobic & \\
\hline & A:TYR251 - B:LIG1 & 4.74 & Pi-Alkyl & Hydrophobic & \\
\hline & A:TYR251 - B:LIG1 & 5.27 & Pi-Alkyl & Hydrophobic & \\
\hline & A:TYR251 - B:LIG1:C & 4.86 & Pi-Alkyl & Hydrophobic & \\
\hline \multirow{6}{*}{$\begin{array}{l}\text { EGFR }+\alpha- \\
\text { tomatine }+ \\
\text { tomatidine } \\
+ \text { EGF }\end{array}$} & A:LYS269:HN- B:UNK0:O14 & 2.93 & $\begin{array}{l}\text { Conventional } \\
\text { Hydrogen Bond }\end{array}$ & $\begin{array}{l}\text { Hydrogen } \\
\text { Bond }\end{array}$ & \multirow{6}{*}{-669.1} \\
\hline & A:LYS270:HZ1-B:UNK0:O16 & 2.89 & $\begin{array}{l}\text { Conventional } \\
\text { Hydrogen Bond }\end{array}$ & $\begin{array}{l}\text { Hydrogen } \\
\text { Bond }\end{array}$ & \\
\hline & B:UNK0:H154 - A:CYS267:O & 2.52 & $\begin{array}{l}\text { Conventional } \\
\text { Hydrogen Bond }\end{array}$ & $\begin{array}{l}\text { Hydrogen } \\
\text { Bond }\end{array}$ & \\
\hline & B:UNK0:H147 - A:CYS267:O & 2.98 & $\begin{array}{l}\text { Conventional } \\
\text { Hydrogen Bond }\end{array}$ & $\begin{array}{l}\text { Hydrogen } \\
\text { Bond }\end{array}$ & \\
\hline & A:LYS407 - B:UNK0 & 4.66 & Alkyl & Hydrophobic & \\
\hline & B:TYR251 - B:UNK0:C41 & 5.26 & Pi-Alkyl & Hydrophobic & \\
\hline EGFR + & B:LIG1:H - A:ARG405:O & 2.57 & Conventional & Hydrogen & -664.7 \\
\hline
\end{tabular}




\begin{tabular}{|c|c|c|c|c|c|}
\hline Interaction & Point Interaction & $\begin{array}{l}\text { Distance } \\
(\AA)\end{array}$ & Type & $\begin{array}{l}\text { Chemistry } \\
\text { Bond }\end{array}$ & $\begin{array}{c}\text { Energy } \\
\text { Binding } \\
\text { (kcal/mol) }\end{array}$ \\
\hline \multirow{7}{*}{$\begin{array}{l}\text { tomatidine } \\
+\alpha- \\
\text { tomatine }+ \\
\text { EGF }\end{array}$} & \multirow[b]{2}{*}{ B:LIG1:H - A:LEU38:O } & \multirow[b]{2}{*}{2.42} & Hydrogen Bond & Bond & \\
\hline & & & $\begin{array}{l}\text { Carbon Hydrogen } \\
\text { Bond }\end{array}$ & $\begin{array}{l}\text { Hydrogen } \\
\text { Bond }\end{array}$ & \\
\hline & B:LIG1:C - A:LYS407 & 3.68 & Alkyl & Hydrophobic & \\
\hline & B:LIG1:C - A:PRO272 & 3.98 & Alkyl & Hydrophobic & \\
\hline & A:PHE263 - B:LIG1:C & 5.30 & Pi-Alkyl & Hydrophobic & \\
\hline & A:PHE263 - B:LIG1:C & 4.60 & Pi-Alkyl & Hydrophobic & \\
\hline & B:TYR251 - B:LIG1 & 5.42 & Pi-Alkyl & Hydrophobic & \\
\hline
\end{tabular}

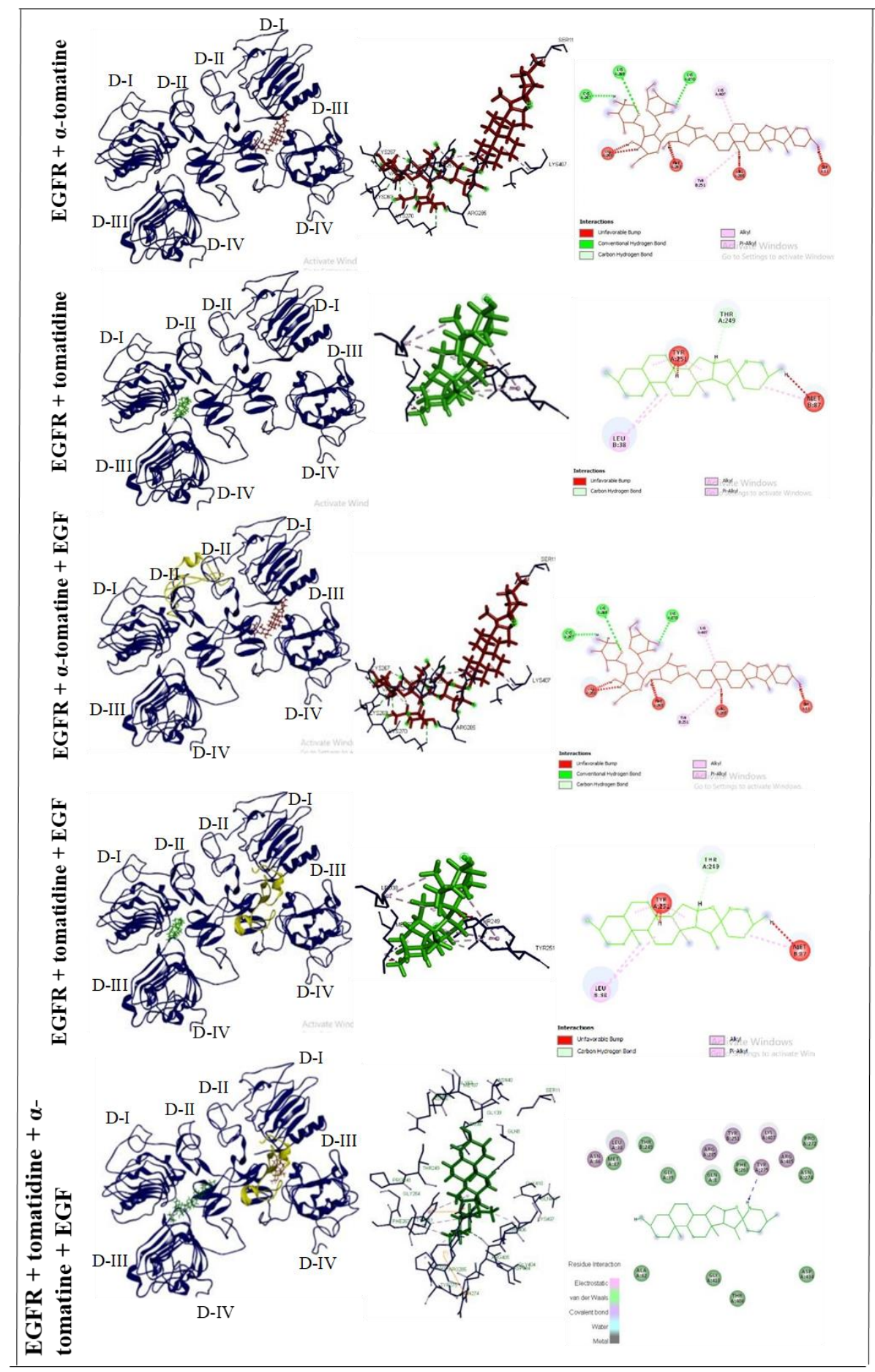

Figure 2. Interaction of EGFR with 4 domains (D-I: domain I; D-II: domain II; D-III: domain III; and D-IV: domain IV) and ligands. Left section shows the binding location among EGF (yellow), $\alpha$-tomatine (red), and tomatidine (green) to EGFR (blue). Middle section shows ligands interaction with amino acid residues of EGFR. Right section shows 2D diagram of the interaction 
Domains II (or CR1) and IV (or CR2) are both cysteine-rich regions with disulfide bonds similar to those seen in laminin and the tumor necrosis factor receptor. Its intracellular Domains residues are known to be phosphorylated. These phosphotyrosine residues bind soluble or membrane-anchored effector proteins that are recruited upon receptor activation. EGFR activates several downstream signaling cascades, which include pathways mediated by Ras/Raf/MAP kinase, phosphoinositide-3-kinase (PI3K)/Akt, and phospholipase $\mathrm{C} \gamma$. Upon ligand binding, the $\mathrm{C}$-terminal tail becomes tyrosinephosphorylated and mediates the interaction between the receptor and downstream effectors $[14,16]$.

In this study showed that tomatidine and combination of both tomatidine and $\alpha$-tomatine can bind in the active site of EGFR which means they can inhibit EGFR to bind with its ligands. This interaction may downregulate the activation of EGFR in cancer especially NSCLC. Alpha tomatine did not bind in the active site independently but this compound has the potential to inhibit EGFR when combined with tomatidine. Previous studies showed that tomatidine which

\section{CONCLUSION}

The $\alpha$-tomatine and tomatidine have potential as inhibitors of the interaction between EGFR and EGF as native ligands. These two compounds were proven to bind with EGFR in their ligand binding site. Combination of $\alpha$-tomatine and tomitidine had shown the best results among other

\section{ACKNOWLEDGEMENT}

The Authors would like to thank all Bioinformatics lecturers of Brawijaya University and assistants for their guidance, advice, and support on our research. Also we send our regards to our research group for helping the authors for finishing this research.

\section{REFERENCES}

1. WHO. 2018. Cancer. Retrieved from https://www.who.int/news-room/factsheets/detail/cancer.

2. Siegel, R. L., Miller, K. D., Jem, A. 2019. Cancer Statistic, 2019. CA Cancer J Clin. 69(1):7-34.

3. Nigro, E., Imperlini, E., Scudiero, O., Monaco, M. L., Polito, R., Mazzarella, G., Orrù, S., Bianco, A., Daniele, A. 2015. Differentially expressed and activated proteins associated with non small cell lung cancer tissues. Respir Res. 16(74):1-10.

4. Li, F., Liu, Y., Chen, H., Liao, D., Shen, Y., Xu, F., Wang, J. 2011. EGFR and COX-2 protein expression in non-small cell lung cancer and the correlation with clinical features Journal of Experimental \& Clinical Cancer Research. 30(27): 1-8. was found widely in green tomatoes and will be degraded along the time tomatoes turn red [17], has an effect to cancer cell lines. In several human cancer cells, tomatidine has proven blocking the $\mathrm{G}_{0} / \mathrm{G}_{1}$ phase which is directly related to EGFR [18]. Lots of studies have evaluated the anticancer activity of $\alpha$-tomatine. Alpha tomatine showed the highest inhibitory effect against HER2 in lung cancer. Alpha tomatine also inhibited EGFRs by binding on its kinase domains [19]. Same as tomatidine, $\alpha$-tomatine was found abundant in green tomatoes. Low amount of $\alpha$ tomatine will be found in red tomatoes due to the degradation process when tomatoes turn red [16]. Alpha tomatine is a glycoalkaloid consist of aglycones i.e. tomatidine and glycoside i.e. betalycotetratose. The glycone of $\alpha$-tomatine consist of 2 glucoses, 1 galactose, and 1 xylose which will establish branch and bind with C-3 of aglycone. The glycone component of $\alpha$-tomatine plays an important role in growth and helps sending signals to induce apoptosis whereas tomatidine as the aglycone of $\alpha$-tomatine will interact with cholesterol forming complexes in cell membranes. This complex can disturb cancer cell membranes [20].

complex that was tested with threads of alpha tomatine applied before tomatidine. Alpha tomatine and tomatidine can be considered as drugs that can control overexpression of EGFR and decrease the activation of one of lung cancers signaling pathways.

5. Villalobos, P. \& Wistuba, I. I. 2017. Lung Cancer Biomarkers. Hematol Oncol Clin North Am. 31(1):13-29.

6. Cancer Research UK. 2019. Gefitinib (Iressa). Retrieved https://www.cancerresearchuk.org/aboutcancer/cancer-in-general/treatment/cancerdrugs/drugs/gefitinib.

7. Friedman, M. 2013. Anticarcinogenic, Cardioprotective, and Other Health Benefits of Tomato Compounds Lycopene, a Tomatine, and Tomatidine in Pure Form and in Fresh and Processed Tomatoes. J. Agric. Food Chem. 61:9534-9550.

8. Pinela, J., Oliveira, M. P. P., Ferreira, I. C. F. R. 2016. Bioactive Compounds of Tomatoes as Healt Promoters. In: Natural Bioactive Compounds from Fruits and Vegetables. Bragança: Bentham Science Publishers.48-91.

9. Beltran, N. P. S. et al. 2015. Total Phenolic, Flavonoid, Tomatine, and Tomatidine Content and Antioxidant and Antimicrobial Activities of Extracts of Tomato Plant. International Journal of Analytical Chemistry. 1-10.

10. Dassault Systemes BIOVIA. 2017. BIOVIA Discovery Studio 2016 [Computer Software]. Retrieved from https://3dsbiovia.com.

11. MNAM. 2020. Online Demo-Fast 3D Structure. Retrieved from https://www.mnam.com/online_demos/corina_demo. 
12. Dallakyan S., \& Olson A. J. 2015. Small-Molecule Library Screening by Docking with PyRx. Methods Mol Biol. 1263:243- 250.

13. Ritchie D. W. 2013. Evaluation of protein docking predictions usin Hex 3.1 in CAPRI rounds 1 and 2. Proteins Struct. Funct. Genet. 39:178-194.

14. Wee, P. \& Wang, Z. 2017. Epidermal Growth Factor Receptor Cell Proliferation Signaling Pathways. Cancers. 9(52):2-4.

15. Sucha, L., Hroch, M., Rezacova, M., Rudolf, E., Havelek, R., Sispera, L. 2013. The Cytotoxic of $\alpha-$ tomatine in MCF-7 human adenocarcinoma breast cancer cells depends on its interaction with cholesterol in incubation media and does not involve apoptosis induction. Oncol Rep. 30(6):2593- 2602.

16. Purba, E. R., Saita, E., Maruyama, I. N. 2017. Activation of The EGF Receptor by Ligand Binding and Oncogenic Mutations: The "Rotation Model". Cells. 6(13):1-19.
17. Friedman, M., Levin, C. E., Lee, S. U., Kim, H. J., Lee, I. S., Byun, J. O., Kozukue, N. 2009. Tomatine-Containing Green Tomato Extracts Inhibit Growth of Human Breast, Colon, Liver, and Stomach Cancer Cells. J. Agric. Food. Chem. 57(13):5727-5733.

18. Dey, P., Kundu, A., Chakraborty, H. J., Kar, B., Choi, W. S., Lee, B. M., Bhakta, T., Atanasov, A. G., Kim, H. S. 2019. Therapeutic value of steroidal alkaloids in cancer: Current trends and future perspectives. Int. J. Cancer. 145:1731-1744.

19. Halil, I. 2020. Antiproliferative Activity of $\alpha$ Tomatine and Molecular Target Identification. Turkish Journal of Agricultural and Natural Sciences. 7(2):290-300.

20. Huang, H., Chen, S., Doren, J. V., Li, D., Farichon, C., He, Y., Zhang, Q., Zhang, K., Conney, A. H., Goddin, S., Du, Z., Zheng, X. 2014. $\alpha$-tomatine inhibits growth and induces apoptosis in HL60 human myeloid leukemia cells. Molecular Medicine Reports. 11:4573-4578. 